Kansas State University Libraries

New Prairie Press

\title{
HOW GOOD ARE SPATIAL GLM'S? A SIMULATION STUDY
}

Roger G. Collins

Walter W. Stroup

Stephen D. Kachman

Follow this and additional works at: https://newprairiepress.org/agstatconference

Part of the Agriculture Commons, and the Applied Statistics Commons

\section{(c) (1) $\Theta$}

This work is licensed under a Creative Commons Attribution-Noncommercial-No Derivative Works 4.0 License.

\section{Recommended Citation}

Collins, Roger G.; Stroup, Walter W.; and Kachman, Stephen D. (1997). "HOW GOOD ARE SPATIAL GLM'S? A SIMULATION STUDY," Conference on Applied Statistics in Agriculture. https://doi.org/10.4148/

2475-7772.1304

This is brought to you for free and open access by the Conferences at New Prairie Press. It has been accepted for inclusion in Conference on Applied Statistics in Agriculture by an authorized administrator of New Prairie Press. For more information, please contact cads@k-state.edu. 


\title{
HOW GOOD ARE SPATIAL GLM'S? A SIMULATION STUDY.
}

\author{
by \\ Roger G. Collins, Walter W. Stroup, and Stephen D. Kachman \\ Department of Biometry \\ University of Nebraska-Lincoln
}

\begin{abstract}
An area of increasing interest to agricultural and ecological researchers is the analysis of spatially correlated non-normal data. A generalized linear model (GLM) accounting for spatial covariance was presented by Gotway and Stroup (1997). Their method included approximate inference based on asymptotic distributions. A simulation study was conducted to assess the small sample behavior of their proposed estimates and test statistics. This study suggests that the spatial GLM yields unbiased estimates of treatment means and differences for binomial data, that the spatial GLM improves precision, as measured by MSE, and that the approximate F-statistic is acceptable for hypothesis testing.
\end{abstract}

\section{INTRODUCTION}

Spatial variability refers to the tendency of adjacent or nearby observations to be more alike than those that are farther apart. Spatial variability occurs in many agricultural and ecological experiments. In recent years, the need for methods to account or adjust for spatial variability has been increasingly appreciated by biological researchers. These methods typically involve modeling spatial correlation among the errors; however, standard spatial correlation methods assume normality. Agricultural and ecological researchers frequently do experiments or studies in which spatial variability is present and the response variable(s) of primary interest are non-normal, e.g. categorical or count data.

The generalized linear model (GLM) presented by Nelder and Wedderburn (1972) is a generalization of linear model theory to non-normal members of the exponential family. Wedderburn (1974), McCullagh (1983), and others extended the GLM approach to more general types of data using quasi-likelihood. Standard GLM's assume independent errors. Zeger and Liang (1986) proposed GLM's for serially correlated observations in repeated measures data.

Gotway and Stroup (1997) proposed a GLM for spatially correlated data. Their approach included approximate inference involving ad hoc adaptations of 
inference for standard GLM's. However, they did not address the small sample properties of these procedures. The purpose of this paper is to present the results of a simulation study to evaluate the behavior of estimates and test-statistics proposed by Gotway and Stroup.

\section{REVIEW OF THE GOTWAY-STROUP METHOD}

The standard GLM assumes an $\mathrm{n} \times 1$ vector of random variables, $\mathbf{y}=\left[\mathrm{y}_{1}, \mathrm{y}_{2}\right.$, $\left.\ldots, y_{n}\right]$, such that $E\left(y_{i}\right)=\mu_{i}$ and $\operatorname{Var}\left(y_{i}\right)=v\left(\mu_{i}\right) a\left(\phi_{i}\right)$ where $v\left(\mu_{i}\right)$ is the variance function and $\mathrm{a}\left(\phi_{\mathrm{i}}\right)$ is the scale parameter. Thus, $\mathrm{E}(\mathbf{y})=\mu$ and $\operatorname{Var}(\mathbf{y})=\mathrm{V}=\mathrm{V}_{\mu}{ }^{1 / 2} \mathrm{AV}_{\mu}{ }^{1 / 2}$, where $\mathrm{V}_{\mu}^{1 / 2}=\operatorname{diag}\left[\operatorname{sqrt}\left(\mathrm{v}\left(\mu_{\mathrm{i}}\right)\right]\right.$ and $\mathrm{A}=\operatorname{diag}\left[\mathrm{a}\left(\phi_{\mathrm{i}}\right)\right]$. The standard GLM is

$\mu=h(X \beta)$

where $X$ is an $n x p$ matrix of known constants, $\beta$ is a $\mathrm{p} \mathrm{x} 1$ parameter vector and $\mathrm{h}(\cdot)$ is the inverse link function.

The spatial GLM proposed by Gotway and Stroup generalizes V, so that $\mathrm{V}(\mathrm{y})=\mathrm{V}_{\mu}^{1 / 2} \mathrm{R}(\alpha) \mathrm{V}_{\mu}^{1 / 2}$, where $\mathrm{R}(\alpha)$ is a "working spatial correlation matrix." Examples of working spatial correlation matrices include semivariogram models, such as the spherical and exponential, commonly used in geostatistics. For example, letting $\mathrm{r}_{\mathrm{ij}}$ be the $\mathrm{ij}^{\mathrm{th}}$ element of $\mathrm{R}(\alpha)$, the spherical model is

$$
\begin{aligned}
& \mathrm{r}_{\mathrm{ij}}=1-0.5\left(\mathrm{~d}_{\mathrm{ij}} / \alpha\right)+1.5\left(\mathrm{~d}_{\mathrm{ij}} / \alpha\right)^{3} \text { if } \mathrm{d}_{\mathrm{ij}}<\alpha, \text { and } \\
& \mathrm{r}_{\mathrm{ij}}=0 \text { if } \mathrm{d}_{\mathrm{ij}}>\alpha,
\end{aligned}
$$

where $\mathrm{d}_{\mathrm{ij}}$ is the distance between the $\mathrm{i}^{\text {th }}$ and $\mathrm{j}^{\text {th }}$ observations.

The parameters of the spatial GLM are estimated by solving the equation $X^{\prime} W X \beta=X^{\prime} W^{*}$

where $y^{*}=X \beta+D^{-1}(y-\mu)$

$\mathrm{D}^{-1}=\operatorname{diag}\left[\partial \mathrm{h}^{-1}\left(\mu_{\mathrm{i}}\right) / \partial \mu_{\mathrm{i}}\right]$, and
$\mathrm{W}=\mathrm{DV}^{-1} \mathrm{D}$.

Approximate inference on estimable functions of the form $\mathbf{K}^{\prime} \beta$ is based on the following asymptotic results:

1. $\operatorname{AV}\left(\mathbf{K}^{\prime} \beta\right)=\mathbf{K}^{\prime}\left(\mathbf{X}^{\prime} \mathbf{W X}\right)^{-1} \mathbf{K}$

2. Hence, for vector $\mathbf{k}$, the asymptotic standard error of $\mathbf{K}^{\prime} \beta$ is

a.s.e. $\left(\mathbf{K}^{\prime} \boldsymbol{\beta}\right)=\operatorname{sqrt}\left[\mathbf{K}^{\prime}\left(\mathbf{X}^{\prime} \mathbf{W} \mathbf{X}\right)^{-1} \mathbf{K}\right]$

3. The Wald statistic for testing $\mathrm{H}_{0}: \mathbf{K}^{\prime} \beta=0$,

$\left(\mathbf{K}^{\prime} \beta\right)^{\prime}\left[\mathbf{K}^{\prime}\left(\mathbf{X}^{\prime} \mathbf{W X}\right) \mathbf{K}\right]^{-1}\left(\mathbf{K}^{\prime} \beta\right)$

is asymptotically $\chi^{2}$ with $\operatorname{rank}(\mathbf{K})$ degrees of freedom. 
4. The Wald statistic divided by $\phi[\operatorname{rank}(\mathbf{K})]$, where $\phi$ is the estimated scale parameter, is asymptotically distributed $\left.\mathrm{F}_{(\mathrm{v} 1, \mathrm{v} 2)}\right)$ where $\mathrm{v}_{1}=\operatorname{rank}(\mathrm{K})$ and $\mathrm{v}_{2}=$ error degrees of freedom. The test statistic Wald $/\{\phi[\operatorname{rank}(\mathbf{K})]\}$ is hereafter referred to as the F-statistic for $\mathrm{H}_{0}: \mathbf{K}^{\prime} \beta=0$.

The Wald and F-statistic produce similar results if $\phi=1$, i.e. if $A=I$ in $\operatorname{Var}(\mathbf{y})$

$=\mathrm{V}_{\mu}^{1 / 2} \mathrm{~A} \mathrm{~V}_{\mu}^{1 / 2}$. However, if $\phi>1$, the Wald statistic will over-reject $\mathrm{H}_{0}$. In the spatial GLM, $\phi>1$ is expected as a result of the contribution of spatial correlation, $R(\alpha)$, to $\operatorname{Var}(\mathbf{y})$ in addition to the variance function $V_{\mu}$.

\section{THE SIMULATION STUDY}

The small sample properties of the spatial GLM were investigated using a simulated experiment consisting of 4 replications of 16 treatments. The treatments were laid out on an $8 \times 8$ grid so that each replication consisted of a $4 \times 4$ balanced lattice (see Figure 1). For each of the 64 experimental units, spatially correlated binomial data were generated as follows:

1. The working correlation matrix $\mathrm{R}(\alpha)$ was determined. In these simulations, the range was set to 3, i.e. $\alpha=3$.

2. Normal deviates were generated for each experimental unit. For the $\mathrm{ij}^{\text {th }}$ experimental unit, corresponding to the $\mathrm{j}^{\text {th }}$ replication $(\mathrm{j}=1,2,3,4)$ of the $\mathrm{i}^{\text {th }}$ treatment $(\mathrm{i}=1,2, \ldots, 16)$, the random deviate is denoted $\mathrm{z}_{\mathrm{ij}}$. To simulate spatial

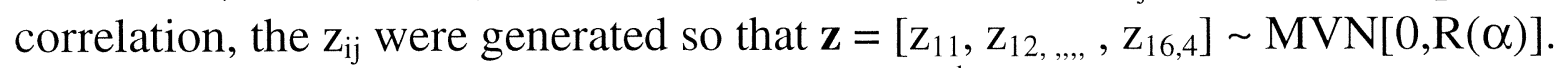

3. The probability of a "success" for the $\mathrm{ij}^{\text {th }}$ experimental unit, denoted $\pi_{\mathrm{ij}}$, was determined as $\pi_{\mathrm{ij}}=\Phi^{-1}\left(\mathrm{z}_{\mathrm{ij}}-\tau_{\mathrm{i}}\right)$, where $\tau_{\mathrm{i}}$ is the effect of the $\mathrm{i}^{\text {th }}$ treatment. Note that $\tau_{\mathrm{i}}$ sets $\pi_{\mathrm{ij}}$ through the inverse normal c.d.f. For example, $\tau_{\mathrm{i}}=0$ would imply that the expected $\pi_{\mathrm{ij}}$ for the $\mathrm{i}^{\text {th }}$ treatment is 0.5 . Several configurations of $\tau_{\mathrm{i}}$ to represent different patterns of treatment effects were used. These are described below.

4. The number of "successes", denoted $y_{i j}$, out of $n_{i j}$ binary observations on the $\mathrm{ij}^{\text {th }}$ experimental unit were generated from a $\operatorname{Bin}\left(\mathrm{n}_{\mathrm{ij}}, \pi_{\mathrm{ij}}\right)$ random number generator. For this simulation, $\mathrm{n}_{\mathrm{ij}}$ was set to either 10 or 50 .

The data were generated with the 17 different $\tau$ vectors that appear in Table 1. The $\tau$ vectors used represent a mix of equal treatment effects and unequal treatment effects. The equal treatment effect vectors represent a spectrum from low probability of a success $(\tau=-1.5)$ to high probability $(\tau=1.5)$. The unequal 
treatment effect vectors represent some scenarios where treatment effects are relatively close and others where treatment effects are farther apart.

A Fortran program was written to generate the data and compute the analysis. The random number generators IGNBIN, to generate binomial random deviates, and AS 66, to evaluate the tail area of the standardized normal curve, that were used in the Fortran program were acquired from http://lib.stat.cmu.edu/apstat/. The data were analyzed using a standard GLM, i.e. where the range, $\alpha=0$, and hence $\mathrm{R}(\alpha)=\mathrm{I}$, and using a spatial GLM with range equal 3. The authors are aware of no programs available at the present time to perform this type of analysis. The current option is to write one's own code in Fortran, C++, or SAS IML. Fortran was chosen for its speed in performing this type of analysis.

Analyses using the standard $[\mathrm{R}(0)]$ and spatial $[\mathrm{R}(3)]$ GLM were compared using the following criteria:

1. The mean and MSE of the estimated $\pi_{\mathrm{i}}$ and four selected differences, $\pi_{\mathrm{i}^{-}}$ $\pi_{\mathrm{i}}$ : the four differences used were, Treatment 1 versus Treatment 2 , Treatment 1 versus Treatment 5, Treatment 1 versus Treatment 10, and Treatment 1 versus Treatment 15.

2. The percent rejection rate of the Wald tests for overall equal means and four differences.

3. The percent rejection rate of the $\mathrm{F}$ tests for overall equal means and four differences. These four differences were chosen because they represent groups of direct and indirect comparisons for the balanced lattice design that was used.

Of particular interest was how well the quantiles of the estimates fit the expected asymptotic quantiles under theory. Theory predicts that the estimated $\pi_{\mathrm{i}}$ and $\pi_{\mathrm{i}}-\pi_{\mathrm{i}}$, are distributed normally. Under $\mathrm{H}_{0}$, the Wald statistic is asymptotically $\chi^{2}$, and the Wald statistic adjusted for $\phi$ is asymptotically F. For the vectors with equal treatment means, the distributions were checked by comparing the observed $5^{\text {th }}, 25^{\text {th }}, 75^{\text {th }}, 95^{\text {th }}$ quantiles with the expected quantiles.

\section{RESULTS}

Table 2 gives the estimated MSE, bias, \% rejection rate of Wald tests, $\%$ rejection rate of $F$ tests, and the number of simulated experiments whose spatial GLM estimation algorithm converged for each combination at $\mathrm{n}_{\mathrm{ij}}=10$ level. MSE is consistently lower for the spatial GLM than for the standard GLM. Both procedures show negligible bias. As expected, the Wald statistic uncorrected for 
overdispersion is biased upward, resulting in excessive rejection rates. On the other hand, the $\mathrm{F}$ tests in the table show more reasonable rejection rates. There is a tendency for the spatial GLM to come closer than the standard GLM to the nominal 5\% level when the null hypothesis is true. The spatial GLM algorithm was deemed to have converged if the convergence criteria was met after 20 iterations. Generally, this occurred over $95 \%$ of the time. Inspection of the cases that failed to converge indicate that convergence would have occurred if the iterations continued a few more rounds.

Table 3 gives the estimated MSE, bias, \% rejection rate of Wald tests, \% rejection rate of $\mathrm{F}$ tests, and the number of iterations that converged for each combination at $\mathrm{n}_{\mathrm{ij}}=50$ level. The results are generally similar to those observed when $n_{i j}=10$. The only difference between $n_{i j}=50$ and $n_{i j}=10$ is that the $F$ tests seem to be closer to the nominal $5 \%$ level in the $n_{i j}=50$ table.

Table 4 gives the expected quantiles of the $\mathrm{F}$ distribution under $\mathrm{H}_{\mathrm{o}}$ and the observed quantiles of the F-statistics for the mean vectors where treatment effects were equal. For both $\mathrm{n}_{\mathrm{ij}}=10$ and $\mathrm{n}_{\mathrm{ij}}=50$, the empirical distribution of the F-statistics show reasonable agreement with the expected quantiles.

\section{DISCUSSION}

1. The uncorrected Wald statistics are strongly biased upward, producing excessive rejection rates. In no case did the Wald statistic give reliable results.

2. Under $\mathrm{H}_{0}$, the $\mathrm{F}$ tests using the spatial GLM appear to come close to the nominal 5\% level when spatial error structure is included in the analysis.

3. In general, when $\mathrm{H}_{\mathrm{o}}$ is false, including the spatial structure of the errors in the GLM results in more powerful $F$ tests.

4. Finally, and most importantly it appears that the small sample behavior of the $\mathrm{F}$ tests are consistent with their expected behavior under asymptotic theory. This result gives credibility to the use of approximate F-statistics for hypothesis testing in spatial GLM's.

5. Taking (1) through (4) together, we strongly recommend use of the approximate $\mathrm{F}$ rather than the Wald statistic for hypothesis testing in spatial GLM's.

6. Spatial GLM appears to produce unbiased estimates of treatment means and differences.

7. MSE of estimates of $\pi_{\mathrm{i}}, \pi_{\mathrm{i}}-\pi_{\mathrm{i}}$, are lower for spatial GLM than for standard GLM. 
The main result of this study was to examine the small-sample properties of the spatial GLM proposed by Gotway and Stroup (1997). The results suggest that the estimates of treatment means and differences are unbiased and reduce MSE compared to standard GLM alternatives when spatial variation is present. More importantly, they suggest that the small-sample behavior of the approximate Fstatistic is acceptable for use in hypothesis testing.

Although these results are promising, more work needs to be done. These results apply to cases where the response is binary, and the spatial correlation model and the range are known. In the future, we plan to investigate the behavior on the spatial GLM when the range is estimated and when the model is misspecified. Also, we plan to look at variety of designs and response variable distributions.

These results only compared the spatial GLM to a standard GLM. We also plan to compare the spatial GLM to non-GLM alternatives. In this simulation, for instance, we plan to compare the spatial GLM to the standard ANOVA for a lattice design with the percent of successes per experimental unit as the response variable and the arc-sine square root transformation, as would likely be standard practice for most researchers.

Finally, a main feature of the Gotway and Stroup (1997) article was a method for spatial prediction. The small sample properties of this method were not addressed in this study. We plan to address them in future studies. 
Figure 1. Example Layout of Simulated $4 \times 4$ Lattice Experiment in 4 Replications. Double-Lines demark complete replications.

\begin{tabular}{|c|c|c|c|c||c|c|c|c|}
\hline RowiColumn & 1 & 2 & 3 & 4 & 5 & 6 & 7 & 8 \\
\hline 1 & Trt 4 & Trt 2 & Trt 8 & Trt 7 & Trt 9 & Trt 13 & Trt 8 & Trt 16 \\
\hline 2 & Trt 3 & Trt 1 & Trt 6 & Trt 5 & Trt 5 & Trt 1 & Trt 12 & Trt 4 \\
\hline 3 & Trt 15 & Trt 16 & Trt 9 & Trt 10 & Trt 11 & Trt 3 & Trt 10 & Trt 6 \\
\hline 5 & Trt 14 & Trt 13 & Trt 12 & Trt 11 & Trt 7 & Trt 15 & Trt 2 & Trt 14 \\
\hline 6 & Trt 2 & Trt 5 & Trt 6 & Trt 11 & Trt 2 & Trt 13 & Trt 9 & Trt 6 \\
\hline 7 & Trt 15 & Trt 12 & Trt 1 & Trt 16 & Trt 11 & Trt 8 & Trt 15 & Trt 4 \\
\hline 8 & Trt 7 & Trt 10 & Trt 14 & Trt 9 & Trt 10 & Trt 3 & Trt 14 & Trt 1 \\
\hline
\end{tabular}


Table 1. Vectors of treatment effects $\left(\tau_{i}\right)$. P success $\}=\Phi^{-1}\left(z_{i j}-\tau_{i}\right)$, where $z \sim M V N(0, R)$

\begin{tabular}{|c|c|c|c|c|c|c|c|c|c|c|c|c|c|c|c|c|}
\hline & Trt 1 & Trt 2 & Trt 3 & Trt 4 & Trt 5 & Trt 6 & Trt 7 & Trt 8 & Trt 9 & Trt 10 & Trt 11 & Trt 12 & Trt 13 & Trt 14 & Trt 15 & Trt 16 \\
\hline A & -1 & -1 & -1 & -1 & 0 & 0 & 0 & 0 & 1 & 1 & 1 & 1 & 1 & 1 & 1 & 1 \\
\hline B & -1 & -1 & -1 & -1 & 1 & 1 & 1 & 1 & 0 & 0 & 0 & 0 & 0 & 0 & 0 & 0 \\
\hline C & 0 & 0 & 0 & 0 & -1 & -1 & -1 & -1 & 1 & 1 & 1 & 1 & 1 & 1 & 1 & 1 \\
\hline D & 0 & 0 & 0 & 0 & -0.5 & -0.5 & -0.5 & -0.5 & 0.5 & 0.5 & 0.5 & 0.5 & 0.5 & 0.5 & 0.5 & 0.5 \\
\hline$E$ & -1 & -1 & -1 & -1 & -0.5 & -0.5 & -0.5 & -0.5 & 0.5 & 0.5 & 0.5 & 0.5 & 0.5 & 0.5 & 0.5 & 0.5 \\
\hline $\mathrm{F}$ & -1 & -1 & -1 & -1 & -1 & -1 & -1 & -1 & 0 & 0 & 0 & 0 & 0 & 0 & 0 & 0 \\
\hline $\mathrm{G}$ & -1 & -1 & -1 & -1 & -1 & -1 & -1 & -1 & 1 & 1 & 1 & 1 & 1 & 1 & 1 & 1 \\
\hline $\mathrm{H}$ & -0.5 & -0.5 & -0.5 & -0.5 & -0.5 & -0.5 & -0.5 & -0.5 & 0.5 & 0.5 & 0.5 & 0.5 & 0.5 & 0.5 & 0.5 & 0.5 \\
\hline 1 & -1 & 0 & 0 & 0 & 0.5 & 0.5 & 0.5 & 0.5 & 1 & 1 & 1 & 1 & 1 & 1 & 1 & 1 \\
\hline $\mathrm{J}$ & -1 & 0 & 0 & 0 & 1 & 1 & 1 & 1 & 0.5 & 0.5 & 0.5 & 0.5 & 0.5 & 0.5 & 0.5 & 0.5 \\
\hline $\mathrm{K}$ & -1 & -0.5 & -0.5 & -0.5 & 0 & 0 & 0 & 0 & 0.5 & 0.5 & 0.5 & 0.5 & 0.5 & 0.5 & 0.5 & 0.5 \\
\hline$L$ & -1 & -0.5 & -0.5 & -0.5 & 0 & 0 & 0 & 0 & 1 & 1 & 1 & 1 & 1 & 1 & 1 & 1 \\
\hline M & -1.5 & -1.5 & -1.5 & -1.5 & -1.5 & -1.5 & -1.5 & -1.5 & -1.5 & -1.5 & -1.5 & -1.5 & -1.5 & -1.5 & -1.5 & -1.5 \\
\hline $\mathrm{N}$ & 1.5 & 1.5 & 1.5 & 1.5 & 1.5 & 1.5 & 1.5 & 1.5 & 1.5 & 1.5 & 1.5 & 1.5 & 1.5 & 1.5 & 1.5 & 1.5 \\
\hline O & 0 & 0 & 0 & 0 & 0 & 0 & 0 & 0 & 0 & 0 & 0 & 0 & 0 & 0 & 0 & 0 \\
\hline$P$ & -1 & -1 & -1 & -1 & -1 & -1 & -1 & -1 & -1 & -1 & -1 & -1 & -1 & -1 & -1 & -1 \\
\hline Q & 1 & 1 & 1 & 1 & 1 & 1 & 1 & 1 & 1 & 1 & 1 & 1 & 1 & 1 & 1 & 1 \\
\hline
\end{tabular}


Table 2. Simulation results for standard vs. spatial $G L M, n i j=10$.

Convergence, MSE of estimates, and \% rejection of $F$ statistics.

\begin{tabular}{|c|c|c|c|c|c|c|c|c|c|c|c|c|c|c|}
\hline \multicolumn{3}{|c|}{ Converged } & MSE & \multicolumn{3}{|c|}{$\begin{array}{l}\text { Overall F } \\
\% \text { rejection }\end{array}$} & \multicolumn{2}{|c|}{$\begin{array}{c}F \text { diff } 1 \\
\% \text { rejection }\end{array}$} & \multicolumn{2}{|c|}{$\begin{array}{c}F \text { diff } 2 \\
\% \text { rejection }\end{array}$} & \multicolumn{2}{|l|}{$\begin{array}{c}\mathrm{F} \text { diff } 3 \\
\% \text { rejection }\end{array}$} & \multicolumn{2}{|c|}{$\begin{array}{c}F \text { diff } 4 \\
\% \text { rejection }\end{array}$} \\
\hline $\begin{array}{l}\text { Sets } \\
\text { of } \tau_{\mathrm{i}}\end{array}$ & $\begin{array}{c}\text { Standaro } \\
\text { GLM }\end{array}$ & $\begin{array}{c}\text { Spatial } \\
\text { GLM }\end{array}$ & $\begin{array}{c}\text { Standard } \\
\text { GLM }\end{array}$ & $\begin{array}{c}\text { Spatial } \\
\text { GLM }\end{array}$ & $\begin{array}{c}\text { Standard } \\
\text { GLM }\end{array}$ & $\begin{array}{c}\text { Spatial } \\
\text { GLM }\end{array}$ & $\begin{array}{c}\text { Standard } \\
\text { GLM }\end{array}$ & $\begin{array}{c}\text { Spatial } \\
\text { GLM }\end{array}$ & $\begin{array}{c}\text { Standard } \\
\text { GLM }\end{array}$ & $\begin{array}{c}\text { Spatial } \\
\text { GLM }\end{array}$ & $\begin{array}{c}\text { Standard } \\
\text { GLM }\end{array}$ & $\begin{array}{c}\text { Spatial } \\
\text { GLM }\end{array}$ & $\begin{array}{c}\text { Standard } \\
\text { GLM }\end{array}$ & $\begin{array}{c}\text { Spatial } \\
\text { GLM }\end{array}$ \\
\hline$n_{i j}=10$ & range $=0$ & range $=3$ & range $=0$ & range $=3$ & range $=0$ & range $=3$ & range $=0$ & range $=3$ & range $=0$ & range $=3$ & range $=0$ & range $=3$ & range $=0$ & range $=3$ \\
\hline$A$ & 1000 & 956 & 0.01466 & 0.01175 & $98.1 \%$ & $100.0 \%$ & $2.0 \%$ & $3.7 \%$ & $43.9 \%$ & $61.4 \%$ & $94.7 \%$ & $98.7 \%$ & $95.0 \%$ & $99.0 \%$ \\
\hline$B$ & 1000 & 963 & 0.01822 & 0.01499 & $90.4 \%$ & $99.8 \%$ & $0.7 \%$ & $2.1 \%$ & $93.5 \%$ & $98.5 \%$ & $35.1 \%$ & & $36.0 \%$ & $52.6 \%$ \\
\hline $\mathrm{C}$ & 1000 & 956 & 0.01409 & 0.01178 & $98.9 \%$ & $100.0 \%$ & $7.8 \%$ & $11.3 \%$ & $41.3 \%$ & $56.4 \%$ & $42.3 \%$ & $61.1 \%$ & $40.1 \%$ & $60.5 \%$ \\
\hline D & 1000 & 992 & 0.01997 & 0.01551 & $34.9 \%$ & $85.6 \%$ & $3.5 \%$ & $7.1 \%$ & $10.6 \%$ & $20.6 \%$ & $9.4 \%$ & $21.5 \%$ & $9.2 \%$ & $20.7 \%$ \\
\hline$E$ & 1000 & 972 & 0.01750 & 0.01463 & $89.2 \%$ & $99.7 \%$ & $1.3 \%$ & $2.9 \%$ & $7.6 \%$ & $16.8 \%$ & $74.9 \%$ & $90.9 \%$ & $74.9 \%$ & $88.7 \%$ \\
\hline$F$ & 1000 & 966 & 0.01783 & 0.01417 & & & $0.5 \%$ & & $0.5 \%$ & & $6 \%$ & & $6 \%$ & $56.2 \%$ \\
\hline $\mathrm{G}$ & 1000 & 968 & 0.01184 & 0.01006 & $100.0 \%$ & $100.0 \%$ & $3.1 \%$ & $5.5 \%$ & $2.8 \%$ & $5.0 \%$ & $96.0 \%$ & $99.1 \%$ & $96.9 \%$ & $99.8 \%$ \\
\hline $\mathrm{H}$ & 1000 & 987 & 0.01965 & 0.01533 & $59.8 \%$ & $96.1 \%$ & $2.8 \%$ & $4.8 \%$ & $2.8 \%$ & $5.4 \%$ & $39.8 \%$ & $61.1 \%$ & $37.7 \%$ & $61.3 \%$ \\
\hline 1 & & 954 & 0.01530 & 0.01256 & & & $38.4 \%$ & & $75.1 \%$ & $3 \%$ & $4 \%$ & $99.0 \%$ & $3 \%$ & $\%$ \\
\hline$J$ & 1000 & 959 & 0.01820 & 0.01403 & $52.2 \%$ & $88.5 \%$ & $35.4 \%$ & $\%$ & $90.6 \%$ & $98.9 \%$ & $71.6 \%$ & $89.7 \%$ & $72.6 \%$ & $9 \%$ \\
\hline $\mathrm{K}$ & 1000 & 980 & 0.02002 & 0.01569 & $50.2 \%$ & $94.6 \%$ & $5.7 \%$ & $13.9 \%$ & $32.0 \%$ & $53.0 \%$ & $70.2 \%$ & $89.8 \%$ & $68.4 \%$ & $91.4 \%$ \\
\hline$L$ & 1000 & 961 & 0.01519 & 0.01269 & $94.2 \%$ & $99.9 \%$ & $10.3 \%$ & $15.9 \%$ & $42.0 \%$ & $59.8 \%$ & $95.5 \%$ & $98.6 \%$ & $95.7 \%$ & $99.2 \%$ \\
\hline$M$ & 00 & 937 & 0.00502 & 0.00421 & $8 \%$ & & $5.6 \%$ & $6.4 \%$ & $5.1 \%$ & $7.2 \%$ & $5.6 \%$ & $7.5 \%$ & $.7 \%$ & \\
\hline$N$ & 1000 & 953 & 0.00611 & 0.00506 & $13.5 \%$ & $8.9 \%$ & $4.9 \%$ & $\%$ & $5.3 \%$ & $6.7 \%$ & $5.0 \%$ & $8.0 \%$ & $5.4 \%$ & $8.7 \%$ \\
\hline $\mathrm{O}$ & 1000 & 1000 & 0.02406 & 0.01757 & $0.5 \%$ & $3.4 \%$ & $2.9 \%$ & $6.3 \%$ & $3.0 \%$ & $5.3 \%$ & $2.2 \%$ & $6.2 \%$ & $2.8 \%$ & $5.9 \%$ \\
\hline $\mathrm{P}$ & 1000 & 930 & 0.01079 & 0.00919 & $4.0 \%$ & $3.8 \%$ & $3.1 \%$ & $5.8 \%$ & $3.9 \%$ & $6.3 \%$ & $3.3 \%$ & $6.2 \%$ & $2.4 \%$ & $5.1 \%$ \\
\hline Q & 1000 & 959 & 0.01023 & 0.00792 & $4.7 \%$ & $3.5 \%$ & $3.3 \%$ & $5.7 \%$ & $3.9 \%$ & $5.3 \%$ & $2.7 \%$ & $5.9 \%$ & $3.5 \%$ & $6.3 \%$ \\
\hline
\end{tabular}


Table 2. (Continued) Simulation results for standard vs. spatial GLM, nij=10.

Bias of estimates, and \% rejection of Wald Statistics.

\begin{tabular}{|c|c|c|c|c|c|c|c|c|c|c|c|c|}
\hline \multicolumn{3}{|c|}{ Bias } & \multicolumn{2}{|c|}{$\begin{array}{l}\text { Overall Wald } \\
\% \text { rejection }\end{array}$} & \multicolumn{2}{|c|}{$\begin{array}{l}\text { Wald diff } 1 \\
\% \text { rejection }\end{array}$} & \multicolumn{2}{|c|}{$\begin{array}{l}\text { Wald diff } 2 \\
\% \text { rejection }\end{array}$} & \multicolumn{2}{|c|}{$\begin{array}{l}\text { Wald diff } 3 \\
\% \text { rejection }\end{array}$} & \multicolumn{2}{|c|}{$\begin{array}{l}\text { Wald diff } 4 \\
\% \text { rejection }\end{array}$} \\
\hline $\begin{array}{l}\text { Sets } \\
\text { of } \tau_{\mathrm{i}}\end{array}$ & $\begin{array}{c}\text { Standard } \\
\text { GLM }\end{array}$ & $\begin{array}{l}\text { Spatial } \\
\text { GLM }\end{array}$ & $\begin{array}{c}\text { Standard } \\
\text { GLM }\end{array}$ & $\begin{array}{c}\text { Spatial } \\
\text { GLM }\end{array}$ & $\begin{array}{c}\text { Standard } \\
\text { GLM }\end{array}$ & $\begin{array}{c}\text { Spatial } \\
\text { GLM }\end{array}$ & $\begin{array}{c}\text { Standard } \\
\text { GLM }\end{array}$ & $\begin{array}{c}\text { Spatial } \\
\text { GLM }\end{array}$ & $\begin{array}{c}\text { Standard } \\
\text { GLM }\end{array}$ & $\begin{array}{c}\text { Spatial } \\
\text { GLM }\end{array}$ & $\begin{array}{c}\text { Standard } \\
\text { GLM }\end{array}$ & $\begin{array}{l}\text { Spatial } \\
\text { GLM }\end{array}$ \\
\hline$n_{i j}=10$ & range $=0$ & range $=3$ & range $=0$ & range $=3$ & range $=0$ & range $=3$ & range $=0$ & range $=3$ & range $=0$ & range $=3$ & rans & range $=3$ \\
\hline $\bar{A}$ & -0.00665 & -0.00550 & $18.1 \%$ & $34.4 \%$ & $73.0 \%$ & $89.7 \%$ & $99.8 \%$ & $100.0 \%$ & $99.9 \%$ & $99.9 \%$ & $100.0 \%$ & $100.0 \%$ \\
\hline B & -0.00148 & -0.00391 & $17.2 \%$ & $33.1 \%$ & $99.8 \%$ & $100.0 \%$ & $76.4 \%$ & $88.6 \%$ & $75.5 \%$ & $88.8 \%$ & $100.0 \%$ & $100.0 \%$ \\
\hline D & -0.00198 & -0.00289 & $29.0 \%$ & $38.2 \%$ & $45.9 \%$ & $62.4 \%$ & $44.1 \%$ & $63.2 \%$ & $45.9 \%$ & $61.4 \%$ & $99.8 \%$ & $100.0 \%$ \\
\hline$E$ & 0.00267 & 0.00701 & $17.0 \%$ & $34.2 \%$ & $39.4 \%$ & $56.3 \%$ & $96.3 \%$ & $99.0 \%$ & $95.7 \%$ & $99.4 \%$ & $100.0 \%$ & $100.0 \%$ \\
\hline $\mathrm{F}$ & 0.01028 & 0.01522 & $20.3 \%$ & $35.5 \%$ & $17.7 \%$ & $33.7 \%$ & $76.3 \%$ & $90.1 \%$ & $75.4 \%$ & $90.6 \%$ & $100.0 \%$ & $100.0 \%$ \\
\hline $\mathrm{G}$ & -0.00159 & 0.00 & $16.2 \%$ & $36.3 \%$ & $14.2 \%$ & 35. & $9.7 \%$ & $99.9 \%$ & $99.8 \%$ & $100.0 \%$ & $100.0 \%$ & $100.0 \%$ \\
\hline $\mathrm{H}$ & -0.00121 & 0.00078 & $28.7 \%$ & $40.2 \%$ & $24.8 \%$ & $40.2 \%$ & $78.8 \%$ & $92.2 \%$ & $81.0 \%$ & $90.9 \%$ & $100.0 \%$ & $100.0 \%$ \\
\hline I & -0.01039 & -0.01278 & $76.4 \%$ & $88.6 \%$ & $94.7 \%$ & $99.1 \%$ & $99.5 \%$ & $99.9 \%$ & $99.5 \%$ & $100.0 \%$ & $100.0 \%$ & $100.0 \%$ \\
\hline M & 0.03482 & 0.03471 & $5.2 \%$ & $15.5 \%$ & $5.4 \%$ & $15.9 \%$ & $5.2 \%$ & $16.2 \%$ & $6.3 \%$ & $16.2 \%$ & $20.6 \%$ & $44.3 \%$ \\
\hline$N$ & -0.03392 & -0.03409 & $4.9 \%$ & $16.7 \%$ & $4.4 \%$ & $14.1 \%$ & $4.8 \%$ & $15.2 \%$ & $4.2 \%$ & $15.5 \%$ & $23.2 \%$ & $43.9 \%$ \\
\hline $\mathrm{O}$ & 0.00568 & -0.00023 & $30.5 \%$ & $38.7 \%$ & $31.7 \%$ & $39.2 \%$ & $28.4 \%$ & $41.7 \%$ & $27.4 \%$ & $40.8 \%$ & $94.7 \%$ & $99.6 \%$ \\
\hline$P$ & 0.02039 & 0.02440 & $17.8 \%$ & $31.7 \%$ & $16.5 \%$ & $30.6 \%$ & $16.0 \%$ & $31.4 \%$ & $16.5 \%$ & $29.8 \%$ & $64.1 \%$ & $90.9 \%$ \\
\hline Q & -0.02067 & -0.02135 & $17.9 \%$ & $30.1 \%$ & $17.4 \%$ & $30.4 \%$ & $17.7 \%$ & $31.8 \%$ & $16.1 \%$ & $32.4 \%$ & $64.3 \%$ & $90.8 \%$ \\
\hline
\end{tabular}


Table 3. Simulation results for standard vs. spatial GLM, nij=50.

Converged, MSE of estimates, \% rejection of $F$ statistics.

\begin{tabular}{|c|c|c|c|c|c|c|c|c|c|c|c|c|c|c|}
\hline \multicolumn{3}{|c|}{ Converged } & \multicolumn{4}{|c|}{$\begin{array}{l}\text { Overall F } \\
\% \text { rejection }\end{array}$} & \multicolumn{2}{|c|}{$\begin{array}{c}\mathrm{F} \text { diff } 1 \\
\% \text { rejection }\end{array}$} & \multicolumn{2}{|c|}{$\begin{array}{c}\mathrm{F} \text { diff } 2 \\
\% \text { rejection }\end{array}$} & \multicolumn{2}{|c|}{$\begin{array}{c}\mathrm{F} \text { diff } 3 \\
\% \text { rejection }\end{array}$} & \multicolumn{2}{|c|}{$\begin{array}{c}\mathrm{F} \text { diff } 4 \\
\% \text { rejection }\end{array}$} \\
\hline $\begin{array}{l}\text { Sets } \\
\text { of } \tau_{\mathrm{i}}\end{array}$ & $\begin{array}{c}\text { Standard } \\
\text { GLM }\end{array}$ & $\begin{array}{c}\text { Spatial } \\
\text { GLM }\end{array}$ & $\begin{array}{c}\text { Standard } \\
\text { GLM }\end{array}$ & \begin{tabular}{c|} 
Spatial \\
GLM
\end{tabular} & $\begin{array}{c}\text { Standard } \\
\text { GLM }\end{array}$ & $\begin{array}{c}\text { Spatial } \\
\text { GLM }\end{array}$ & $\begin{array}{c}\text { Standard } \\
\text { GLM }\end{array}$ & \begin{tabular}{c|} 
Spatial \\
GLM
\end{tabular} & $\begin{array}{c}\text { Standard } \\
\text { GLM }\end{array}$ & $\begin{array}{c}\text { Spatial } \\
\text { GLM }\end{array}$ & $\begin{array}{c}\text { Standard } \\
\text { GLM }\end{array}$ & $\begin{array}{c}\text { Spatial } \\
\text { GLM }\end{array}$ & $\begin{array}{c}\text { Standard } \\
\text { GLM }\end{array}$ & $\begin{array}{c}\text { Spatial } \\
\text { GLM }\end{array}$ \\
\hline$n_{i j}=50$ & range $=0$ & range $=3$ & range $=0$ & range $=3$ & range $=0$ & range $=3$ & range $=0$ & range $=3$ & range $=0$ & range $=3$ & range $=0$ & range $=3$ & 3 range $=0$ & range $=3$ \\
\hline $\bar{A}$ & 1000 & 952 & 0.01366 & 0.00972 & $99.2 \%$ & $100.0 \%$ & $1.3 \%$ & $3.9 \%$ & $45.1 \%$ & $71.4 \%$ & $96.8 \%$ & $100.0 \%$ & $96.2 \%$ & $99.9 \%$ \\
\hline B & 1000 & 965 & 0.01741 & 0.01230 & $91.7 \%$ & $99.9 \%$ & $0.8 \%$ & $2.0 \%$ & $95.3 \%$ & $99.9 \%$ & $40.6 \%$ & $68.2 \%$ & $39.7 \%$ & $71.7 \%$ \\
\hline C & 1000 & 957 & 0.01335 & 0.00952 & $99.2 \%$ & $100.0 \%$ & $5.1 \%$ & $8.8 \%$ & $40.1 \%$ & $68.2 \%$ & $41.8 \%$ & $69.6 \%$ & $42.9 \%$ & $69.4 \%$ \\
\hline D & 1000 & 997 & 0.01938 & 0.01348 & $39.0 \%$ & $95.1 \%$ & $2.6 \%$ & $5.6 \%$ & $10.0 \%$ & $24.6 \%$ & $11.1 \%$ & $27.2 \%$ & $12.3 \%$ & $24.8 \%$ \\
\hline $\mathrm{E}$ & 1000 & 969 & 0.01689 & 0.01190 & $92.2 \%$ & $100.0 \%$ & $0.2 \%$ & $2.2 \%$ & $8.1 \%$ & $16.2 \%$ & $76.8 \%$ & $96.9 \%$ & $76.1 \%$ & $96.2 \%$ \\
\hline $\mathrm{F}$ & 1000 & 945 & 0.01666 & 0.01151 & $67.4 \%$ & $96.4 \%$ & $0.4 \%$ & $2.0 \%$ & $0.3 \%$ & $2.4 \%$ & $39.3 \%$ & $70.6 \%$ & $39.9 \%$ & $71.1 \%$ \\
\hline G & 1000 & 951 & 0.01064 & 0.00815 & $100.0 \%$ & $100.0 \%$ & $2.2 \%$ & $4.6 \%$ & $1.9 \%$ & $3.7 \%$ & $97.6 \%$ & $99.5 \%$ & $97.6 \%$ & $100.0 \%$ \\
\hline $\mathrm{H}$ & 1000 & 998 & 0.01828 & 0.01268 & $68.8 \%$ & $99.5 \%$ & $1.6 \%$ & $4.9 \%$ & $2.8 \%$ & $5.9 \%$ & $45.4 \%$ & $75.4 \%$ & $44.9 \%$ & $76.7 \%$ \\
\hline 1 & 1 & 937 & 0.0 & 0.01056 & $72.7 \%$ & $99.5 \%$ & $40.0 \%$ & $70.2 \%$ & $76.5 \%$ & $96.9 \%$ & $95.1 \%$ & $99.9 \%$ & $96.3 \%$ & $99.8 \%$ \\
\hline$J$ & 0 & 954 & 22 & 0.01135 & $7 \%$ & $97.1 \%$ & $36.9 \%$ & $72.2 \%$ & $95.0 \%$ & $99.9 \%$ & $75.5 \%$ & $96.8 \%$ & $75.7 \%$ & $97.2 \%$ \\
\hline K & 0 & 983 & & 0.01 & $\%$ & $98.3 \%$ & $4.8 \%$ & $15.8 \%$ & $32.8 \%$ & $67.0 \%$ & $75.5 \%$ & $96.8 \%$ & $72.6 \%$ & $95.8 \%$ \\
\hline $\mathrm{L}$ & & 946 & & 0.0 & $\%$ & $100.0 \%$ & $8.3 \%$ & $20.5 \%$ & $43.0 \%$ & $69.8 \%$ & $95.5 \%$ & $99.7 \%$ & $96.5 \%$ & $100.0 \%$ \\
\hline M & & 729 & 73 & 0.00271 & & & $2.2 \%$ & $5.9 \%$ & $2.2 \%$ & $4.9 \%$ & $1.1 \%$ & $\%$ & $1.4 \%$ & $6.4 \%$ \\
\hline $\mathrm{N}$ & & 792 & 0.00493 & 0.00354 & $10.1 \%$ & $1.1 \%$ & $1.9 \%$ & $3.4 \%$ & $3.1 \%$ & $3.3 \%$ & $1.8 \%$ & $5.1 \%$ & $2.4 \%$ & $4.5 \%$ \\
\hline $\mathrm{O}$ & 1 & 1000 & 0.02265 & 0.01501 & & $2.7 \%$ & $2.6 \%$ & $4.3 \%$ & $2.9 \%$ & $3.9 \%$ & $2.4 \%$ & $4.4 \%$ & $1.6 \%$ & $4.5 \%$ \\
\hline$P$ & 1 & 903 & & 0.00740 & & $1.2 \%$ & $1.4 \%$ & $4.4 \%$ & $1.3 \%$ & $4.4 \%$ & $0.7 \%$ & $4.7 \%$ & $1.7 \%$ & $4.1 \%$ \\
\hline Q & 1000 & 948 & 0.00956 & 0.00648 & $1.8 \%$ & $0.9 \%$ & $1.4 \%$ & $4.0 \%$ & $2.4 \%$ & $2.8 \%$ & $1.5 \%$ & $3.6 \%$ & $0.6 \%$ & $3.9 \%$ \\
\hline
\end{tabular}


Table 3. (Continued) Simulation results for standard vs. spatial GLM, nij=50. Bias of estimates, \% rejection of Wald statistics.

\begin{tabular}{|c|c|c|c|c|c|c|c|c|c|c|c|c|}
\hline \multicolumn{3}{|c|}{ Bias } & \multicolumn{2}{|c|}{$\begin{array}{l}\text { Overall Wald } \\
\% \text { rejection }\end{array}$} & \multicolumn{2}{|c|}{$\begin{array}{l}\text { Wald diff } 1 \\
\% \text { rejection }\end{array}$} & \multicolumn{2}{|c|}{$\begin{array}{l}\text { Wald diff } 2 \\
\% \text { rejection }\end{array}$} & \multicolumn{2}{|c|}{$\begin{array}{l}\text { Wald diff } 3 \\
\% \text { rejection }\end{array}$} & \multicolumn{2}{|c|}{$\begin{array}{l}\text { Wald diff } 4 \\
\% \text { rejection }\end{array}$} \\
\hline $\begin{array}{l}\text { Sets } \\
\text { of } \tau_{\mathrm{i}}\end{array}$ & $\begin{array}{c}\text { Standard } \\
\text { GLM }\end{array}$ & $\begin{array}{l}\text { Spatial } \\
\text { GLM }\end{array}$ & $\begin{array}{c}\text { Standard } \\
\text { GLM }\end{array}$ & $\begin{array}{c}\text { Spatial } \\
\text { GLM }\end{array}$ & $\begin{array}{c}\text { Standard } \\
\text { GLM }\end{array}$ & $\begin{array}{c}\text { Spatial } \\
\text { GLM }\end{array}$ & $\begin{array}{c}\text { Standard } \\
\text { GLM }\end{array}$ & $\begin{array}{c}\text { Spatial } \\
\text { GLM }\end{array}$ & $\begin{array}{c}\text { Standaro } \\
\text { GLM }\end{array}$ & $\begin{array}{c}\text { Spatial } \\
\text { GLM }\end{array}$ & $\begin{array}{c}\text { Standard } \\
\text { GLM }\end{array}$ & $\begin{array}{c}\text { Spatial } \\
\text { GLM }\end{array}$ \\
\hline$n_{i j}=50$ & range $=0$ & range $=3$ & range $=0$ & range $=3$ & range $=0$ & range $=3$ & range $=0$ & range $=3$ & range $=0$ & ran & range $=0$ & $e=3$ \\
\hline $\bar{A}$ & -0.00155 & -0.00050 & $100.0 \%$ & $100.0 \%$ & $56.5 \%$ & $68.9 \%$ & $95.0 \%$ & $98.2 \%$ & $100.0 \%$ & $100.0 \%$ & $100.0 \%$ & $100.0 \%$ \\
\hline B & -0.00150 & -0.00260 & $100.0 \%$ & $100.0 \%$ & $57.0 \%$ & $63.8 \%$ & $99.9 \%$ & $100.0 \%$ & $94.9 \%$ & $98.2 \%$ & $95.1 \%$ & $98.1 \%$ \\
\hline D & -0.00235 & 0.00159 & $100.0 \%$ & $100.0 \%$ & $59.0 \%$ & $68.1 \%$ & $76.4 \%$ & $86.3 \%$ & $77.6 \%$ & $86.6 \%$ & $77.2 \%$ & $86.8 \%$ \\
\hline$E$ & -0.00056 & 0.00075 & $100.0 \%$ & $100.0 \%$ & $57.6 \%$ & $66.4 \%$ & $72.2 \%$ & $83.0 \%$ & $99.8 \%$ & $100.0 \%$ & $99.8 \%$ & $100.0 \%$ \\
\hline $\mathrm{F}$ & 0.00583 & 0.00379 & $100.0 \%$ & $100.0 \%$ & $60.4 \%$ & $66.5 \%$ & $58.1 \%$ & $63.5 \%$ & $93.9 \%$ & $97.8 \%$ & $94.8 \%$ & $98.1 \%$ \\
\hline G & & -0.00029 & & $100.0 \%$ & $59.1 \%$ & & $\%$ & & $100.0 \%$ & $100.0 \%$ & $100.0 \%$ & $100.0 \%$ \\
\hline $\mathrm{H}$ & -0.00051 & 0.00064 & $100.0 \%$ & $100.0 \%$ & $62.7 \%$ & $69.2 \%$ & $62.2 \%$ & $67.3 \%$ & $96.1 \%$ & $98.9 \%$ & $95.5 \%$ & $99.0 \%$ \\
\hline 1 & -0.00442 & -0.00533 & $100.0 \%$ & $100.0 \%$ & $94.1 \%$ & $98.1 \%$ & $99.9 \%$ & $99.9 \%$ & $100.0 \%$ & $100.0 \%$ & $100.0 \%$ & $100.0 \%$ \\
\hline M & 0.00383 & 0.00653 & $98.9 \%$ & $99.5 \%$ & $44.4 \%$ & $58.6 \%$ & $45.8 \%$ & $52.9 \%$ & $44.0 \%$ & $53.4 \%$ & $44.3 \%$ & $59.0 \%$ \\
\hline$N$ & -0.00500 & -0.00660 & $98.5 \%$ & $99.2 \%$ & $48.4 \%$ & $57.1 \%$ & $46.4 \%$ & $52.8 \%$ & $45.4 \%$ & $54.8 \%$ & $46.0 \%$ & $53.2 \%$ \\
\hline $\mathrm{O}$ & 0.00199 & 0.00048 & $100.0 \%$ & $100.0 \%$ & $61.0 \%$ & $68.0 \%$ & $63.6 \%$ & $67.7 \%$ & $60.9 \%$ & $68.3 \%$ & $62.1 \%$ & $63.8 \%$ \\
\hline$P$ & 0.00300 & 0.00680 & $100.0 \%$ & $100.0 \%$ & $57.7 \%$ & $63.9 \%$ & $56.2 \%$ & $63.8 \%$ & $58.1 \%$ & $65.8 \%$ & $58.6 \%$ & $62.1 \%$ \\
\hline Q & -0.00336 & -0.00201 & $100.0 \%$ & $100.0 \%$ & $57.0 \%$ & $63.3 \%$ & $56.5 \%$ & $63.4 \%$ & $60.0 \%$ & $65.1 \%$ & $57.4 \%$ & $65.2 \%$ \\
\hline
\end{tabular}


Table 4. Quantiles of the F Tests for vectors with equal treatment effects.

\begin{tabular}{|c|c|c|c|c|c|c|c|c|c|c|c|c|}
\hline Spatial GLM & \multicolumn{4}{|c|}{ Overall $\mathrm{F}$ quantiles } & \multicolumn{4}{|c|}{ Diff $1 \mathrm{~F}$ quantiles } & \multicolumn{4}{|c|}{ Diff $2 \mathrm{~F}$ quantiles } \\
\hline$n_{i j}=10$ & $5^{\text {th }}$ & $25^{\text {th }}$ & $75^{\text {th }}$ & $95^{\text {th }}$ & $5^{\text {th }}$ & $25^{\text {th }}$ & $75^{\text {th }}$ & $95^{\text {th }}$ & $5^{\text {th }}$ & $25^{\text {th }}$ & $75^{\text {th }}$ & $95^{\text {th }}$ \\
\hline Theoretical & 0.458 & 0.722 & 1.282 & 1.880 & 0.004 & 0.103 & 1.356 & 4.043 & 0.004 & 0.103 & 1.356 & 4.043 \\
\hline $\bar{M}$ & 0.565 & 0.848 & 1.464 & 2.098 & 0.008 & 0.147 & 1.621 & 4.464 & 0.005 & 0.146 & 1.529 & 4.696 \\
\hline $\mathrm{N}$ & 0.564 & 0.842 & 1.449 & 2.249 & 0.004 & 0.150 & 1.887 & 5.190 & 0.003 & 0.135 & 1.720 & 4.821 \\
\hline 0 & 0.492 & 0.761 & 1.280 & 1.748 & 0.003 & 0.106 & 1.507 & 4.349 & 0.005 & 0.096 & 1.505 & 4.233 \\
\hline$P$ & 0.515 & 0.750 & 1.222 & 1.756 & 0.006 & 0.167 & 1.754 & 4.497 & 0.005 & 0.137 & 1.680 & 4.260 \\
\hline Q & 0.490 & 0.752 & 1.231 & 1.745 & 0.006 & 0.126 & 1.635 & 4.329 & 0.008 & 0.143 & 1.569 & 4.202 \\
\hline Spatial GLM & & Diff $3 \mathrm{~F}$ & quantil & & & Diff $4 \mathrm{~F}$ & quantil & & & & & \\
\hline$n_{i j}=10$ & $5^{\text {th }}$ & $25^{\text {th }}$ & $75^{\text {th }}$ & $95^{\text {th }}$ & $5^{\text {th }}$ & $25^{\text {th }}$ & $75^{\text {th }}$ & $95^{\text {th }}$ & & & & \\
\hline Theoretical & 0.004 & 0.103 & 1.356 & 4.043 & 0.004 & 0.103 & 1.356 & 4.043 & & & & \\
\hline$M$ & 0.006 & 0.148 & 1.772 & 5.067 & 0.006 & 0.141 & 1.868 & 4.637 & & & & \\
\hline$N$ & 0.004 & 0.121 & 1.769 & 5.309 & 0.005 & 0.132 & 1.669 & 5.154 & & & & \\
\hline 0 & 0.004 & 0.128 & 1.530 & 4.376 & 0.005 & 0.126 & 1.455 & 4.277 & & & & \\
\hline$P$ & 0.006 & 0.147 & 1.750 & 4.589 & 0.005 & 0.137 & 1.577 & 4.109 & & & & \\
\hline Q & 0.005 & 0.119 & 1.718 & 4.306 & 0.006 & 0.165 & 1.762 & 4.629 & & & & \\
\hline
\end{tabular}

\begin{tabular}{|c|c|c|c|c|c|c|c|c|c|c|c|c|}
\hline Spatial GLM & \multicolumn{4}{|c|}{ Overall F quantiles } & \multicolumn{4}{|c|}{ Diff 1 F quantiles } & \multicolumn{4}{|c|}{ Diff 2 F quantiles } \\
\hline$n_{i j}=50$ & $5^{\text {th }}$ & $25^{\text {th }}$ & $75^{\text {th }}$ & $95^{\text {th }}$ & $5^{\text {th }}$ & $25^{\text {th }}$ & $75^{\text {th }}$ & $95^{\text {th }}$ & $5^{\text {th }}$ & $25^{\text {th }}$ & $75^{\text {th }}$ & $95^{\text {th }}$ \\
\hline Theoretical & 0.458 & 0.722 & 1.282 & 1.880 & 0.004 & 0.103 & 1.356 & 4.043 & 0.004 & 0.103 & 1.356 & 4.043 \\
\hline $\mathrm{M}$ & 0.457 & 0.647 & 1.084 & 1.566 & 0.008 & 0.187 & 1.818 & 4.413 & 0.005 & 0.146 & 1.555 & 4.004 \\
\hline $\mathrm{N}$ & 0.449 & 0.633 & 1.043 & 1.477 & 0.008 & 0.142 & 1.495 & 3.630 & 0.007 & 0.143 & 1.418 & 3.539 \\
\hline $\mathrm{O}$ & 0.442 & 0.718 & 1.228 & 1.684 & 0.007 & 0.112 & 1.359 & 3.666 & 0.004 & 0.110 & 1.415 & 3.640 \\
\hline $\mathrm{P}$ & 0.460 & 0.656 & 1.088 & 1.537 & 0.006 & 0.127 & 1.551 & 3.883 & 0.004 & 0.134 & 1.555 & 3.929 \\
\hline Q & 0.430 & 0.662 & 1.065 & 1.516 & 0.007 & 0.129 & 1.608 & 3.794 & 0.007 & 0.129 & 1.540 & 3.550 \\
\hline Spatial GLM & & Diff $3 \mathrm{~F}$ & quantil & & & Diff $4 \mathrm{~F}$ & quantil & & & & & \\
\hline$n_{i j}=50$ & $5^{\text {th }}$ & $25^{\text {th }}$ & $75^{\text {th }}$ & $95^{\text {th }}$ & $5^{\text {th }}$ & $25^{\text {th }}$ & $75^{\text {th }}$ & $95^{\text {th }}$ & & & & \\
\hline Theoretical & 0.004 & 0.103 & 1.356 & 4.043 & 0.004 & 0.103 & 1.356 & 4.043 & & & & \\
\hline $\mathrm{M}$ & 0.003 & 0.119 & 1.718 & 4.083 & 0.009 & 0.171 & 1.687 & 4.463 & & & & \\
\hline $\mathrm{N}$ & 0.012 & 0.169 & 1.636 & 4.044 & 0.006 & 0.159 & 1.603 & 3.735 & & & & \\
\hline 0 & 0.006 & 0.122 & 1.468 & 3.896 & 0.003 & 0.096 & 1.240 & 3.715 & & & & \\
\hline$P$ & 0.006 & 0.141 & 1.564 & 3.864 & 0.003 & 0.119 & 1.590 & 3.722 & & & & \\
\hline$Q$ & 0.006 & 0.139 & 1.594 & 3.616 & 0.009 & 0.143 & 1.495 & 3.578 & & & & \\
\hline
\end{tabular}




\section{REFERENCES}

Agresti, A. (1990), Categorical Data Analysis. New York: John Wiley.

Gotway, C.A. and Stroup, W.W. (1997), "A generalized linear model approach to spatial data analysis and prediction," Journal of Agricultural, Biological, and Environmental Statistics, 2, 157-178.

Liang, K., and Zeger, S.L. (1986), "Longitudinal data analysis using generalized linear models," Biometrika, 73, 13-22.

Littell, R.C., Milliken, G.A., Stroup, W.W. and Wolfinger, R.D. (1996), SAS System for Mixed Models. SAS Institute, Inc., Cary, NC, 633p.

McCullagh, P. (1983), "Quasi-Likelihood Functions," Annals of Statistics, 11, 5967.

McCullagh, P. and Nelder, J.A. (1989), Generalized Linear Models, Second Edition, New York: Chapman \& Hall.

Nelder, J.A. and Wedderburn, R.W.M. (1972), "Generalized Linear Models," Journal of the Royal Statistical Society, Ser. A, 135, 370-384.

Wedderburn, R.W.M. (1974), "Quasi-likelihood Functions, Generalized Linear Models and the Gauss-Newton Method," Biometrika, 61, 439-447.

Zeger, S.L. and Laing, K. (1986), "Longitudinal data analysis for discrete and continuous outcomes," Biometrics 42, 121-130. 